\author{
Évelyne Diebolt \\ Historiadora e pesquisadora independente
}

\title{
História do trabalho social: nascimento e expansão do setor associativo sanitário e social (França: 1901-2001)
}

\begin{abstract}
Resumo: Sem direitos civis, sem direito a voto, sem a possibilidade de filiar-se a um sindicato e com dificuldades para militar nos partidos políticos, as mulheres encontraram na Lei de $1^{\circ}$ de julho de 1901, sobre a liberdade de associação, uma brecha para ingressar com toda a força na cidadania. Desde a promulgação da Lei de 1901, elas criaram numerosas associações sanitárias e sociais, e foram pioneiras na constituição do conceito de serviço social. Elas fizeram tudo o que foi possível para criar novos empregos, o que contribuiu para a participação exclusivamente feminina no setor. Graças à abertura progressiva das profissões, as populações femininas, alvo das atividades dessas associações, conseguiram inserir-se no mundo do trabalho médico-social. Nos anos 1970, o setor sanitário e social expandiu-se como nunca e manteve a estrutura associativa. Nessas associações, são as mulheres que ocupam a maior parte das vagas, mas se trata de empregos pouco qualificados. Conforme o setor vai se institucionalizando, as mulheres vêem seus empregos escapando de suas mãos para passar para as dos homens. Esse setor associativo hoje em dia é amplamente utilizado pelos poderes públicos para pôr em prática políticas sociais, mas também para lutar contra todas as formas de pobreza e atuar diante de situações de urgência.
\end{abstract}

Palavras-chave: associações femininas, cidadania, serviço social.

Copyright (c) 2005 by Revista Estudos Feministas

Jean-Marie GARRIGOULAGRANGE, 1970 e 1975.
A Lei de $1^{\circ}$ de julho de 1901, sobre a liberdade associativa, define a associação como sendo "a convenção pela qual uma ou várias pessoas colocam em comum e de forma contínua seus conhecimentos ou suas atividades com a única finalidade de dividir os benefícios". A maleabilidade e a simplicidade do texto fundador facilitam sua utilização' e essa lei, que resistiu ao tempo, continuou essencialmente intacta.

Não tendo direitos civis, sem direito de voto, impedidas de aderir a um sindicato e com dificuldade de 
2 Evelyne DIEBOLT e Christiane DOUYERE-DEMULANAERE, 2002.

${ }^{3}$ Genevève POUJOL, 1978 e 1989

${ }^{4}$ DIEBOLT, 2001 a militar em um partido político, as mulheres encontraram nessa lei uma brecha para exercer a cidadania. ${ }^{2}$

Desde a promulgação da Lei de 1901, as mulheres criaram numerosas associações sanitárias e sociais , lutando contra a pobreza, a miséria moral e intelectual, as epidemias e doenças. Elas empreenderam uma tentativa de organizar a sociedade sob uma forma nova - a associação - para obter dos poderes públicos e da sociedade civil a criação de leis sociais nacionais bem como o reconhecimento e o financiamento de ações sociais concretas e imediatas.

Toda associação se posiciona, desde a origem, entre os poderes constituídos fortes e monolíticos. ${ }^{3}$ No setor associativo médico-social esses poderes se definem claramente como sendo, de um lado, as Igrejas, Protestante e Católica, e de outro o Estado. As igrejas, dotadas de uma grande força de inércia, defendem as associações, com mais ou menos vigor, e mesmo mantêm, principalmente a Igreja Católica, um controle sobre elas. Quanto ao Estado, ele é sempre um alvo, seja para obter algo, seja quando sua atuação é considerada muito intervencionista. O Estado atua promulgando conjuntos sucessivos de leis, que provocam uma mudança na paisagem associativa e uma recomposição no jogo de influências. As associações, sempre em luta com as instituições, conseguem mobilizar as forças que as unem no momento desses conflitos.

As associações vivem dos fundos privados da filantropia. ${ }^{4}$ As mulheres pioneiras do movimento souberam valorizar o setor médico social fundando associações variadas e originais tais como as Maisons Sociales (Lares Sociais): I'Union Familiale de Charonne (UFC) (1894) (União Familiar da Charonne), a Résidence Sociale de LevalloisPerret (RSLP) (1908) (Lar Social Levallois-Perret), os hospitaisescolas da Association pour le Développement de l'Assistance aux Malades (ADAM) (Associação para o Desenvolvimento da Assistência aos Doentes em Paris), a Maison de Santé Protestante de Bordeaux (MSP) (1901) (Casa de Saúde Protestante de Bordeaux) e o Hôpital-École Ambroise-Paré de Lille (1921) (Hospital-Escola Ambroise-Paré de Lille).

São fundadas obras sociais como, por exemplo, a de Léonie Chaptal em Paris e outras, que também são lugares de formação profissional. Citemos a Maison-École d'Infirmières Privées (1905) (Casa-Escola de Enfermeiras Privadas), a École Pratique de Service Social (EPSS) (1914) (Escola Prática de Serviço Social), a Association des Infirmières Visiteuses de France (AIV) (1914-1938) (Associação de Enfermeiras Visitadoras da França), a Association d'Hygiène Sociale de l'Aisne (AHSA) (1923) (Associação de Higiene Social de Aisne), que se torna a 
Associação Anne-Morgan (1952) e a Association des Surintendantes d'Usine et des Services Sociaux (1933) (Associação de Superintendentes de Fábricas e Serviços Sociais). Sob o impulso dessas mulheres dinâmicas, tais associações evoluem e se expandem. A Associação para o Desenvolvimento da Assistência aos Doentes (ADAM) em Paris torna-se o Instituto de Serviço Social de Montrouge (1932), contribuindo para o nascimento da Escola de Puericultura da Faculdade de Medicina de Paris (1919).

\section{As atividades médico-sociais das associaçōes}

A vida quotidiana da associação é regulada por várias atividades. Nas associações sanitárias como nos hospitais-escolas são, na maior parte do tempo, as mulheres que assumem os serviços junto à população atendida. Quanto ao trabalho social propriamente dito, que mais comumente se pratica fora da associação (tratamentos domiciliares, campanhas de prevenção contra doenças, colônia de férias, etc.), também é assegurado por mulheres. Podemos citar inúmeras atividades no seio da associação que são assumidas pelas mulheres, tais como empréstimos de livros nas bibliotecas, serviços de secretaria e serviços de limpeza. As mulheres também são responsáveis pelas atividades com crianças, exceto quando se trata de esporte para jovens.

Os tipos de ajuda oferecidos pelas associações são extremamente variados, sendo a prevenção um dos mais importantes. Para realizar esses serviços as mulheres fazem pesquisas, estudam as condições de vida das populações e suas necessidades, organizando, em médio prazo, ações de educação sanitária, educação familiar e cultural. Conselhos jurídicos também podem ser obtidos nas associações. Como benefício imediato, visando à prevenção, as associações oferecem vales para leite e alimentação às jovens mães e seus bebês, assim como "curas através da busca pelo ar puro e da boa alimentação", jardins-de-infância, etc. Medidas de ajuda de urgência, para casos de angústia ou doenças, também são oferecidas.

As associações são lugares onde se pode sempre encontrar ajuda, socorro e assistência, e em algumas as ambições das responsáveis vão além das necessidades imediatas das populações. As mulheres tentam educar o gosto, inculcar o respeito ao belo, tendo a estética como um fator de equilíbrio e de serenidade. Em alguns casos são organizadas atividades culturais, teatro, cinema, esporte, escotismo, leitura (biblio-ônibus em Aisne), festas, etc. 
${ }^{5}$ Sylvie FAYET SCRIBE, 1990, p. 54 e 49. Marie-Jeanne Bassot sempre deu importância à educação e ao aprimoramento estético. Nota-se isso em seus conselhos sobre decoração ou nas seções de trabalhos manuais: bouquet de flores, harmonia do mobiliário..

\footnotetext{
${ }^{6}$ Fauché: gíria francesa que poderia ser traduzida por "estar dura, sem dinheiro" (N.T.)
}

\section{Um trabalho social "integral"}

No espírito de suas fundadoras e de suas líderes está viva a consciência do dever cumprido no esforço para melhorar as condições de vida das populações miseráveis das cidades e do campo. Mas criando esses lares MarieJeanne Bassot vai além: inspirando-se no catolicismo social e na Rerum Novarum, ela pretende romper com a corrente paternalista e tenta desenvolver sua própria concepção do social. Esse termo merece uma redefinição: na época, ele englobou várias atividades que não se limitavam ao setor médico, indo do sanitário ao cultural. O ser humano é, então, tratado na sua totalidade, o que implica um trabalho de educação. Marie-Jeanne Bassot faz sua a frase de Bonald: "A educação começa com a vida, a instrução com a razão... A instrução forma os sábios, a educação forma os homens". ${ }^{5}$ E nas Maisons Sociales o aprimoramento estético ou a participação de conferencistas de renome é tão importante quanto a puericultura. No que se refere ao tratamento dos doentes e dos problemas que lhes são associados, as mulheres constatam que muitos médicos tendem a negligenciar a prevenção, as condições de vida dos doentes, os problemas familiares e sociais dos cidadãos e as dimensões domésticas da doença. As Maisons Sociales ambicionam remediar essa situação e se mostram particularmente eficazes no domínio da proteção da mulher e da infância. Formando seu próprio pessoal, as escolas respondem a essa vasta necessidade social. Ao mesmo tempo colocam no mercado pessoas qualificadas, por elas formadas, para difundir essas novas necessidades, e denunciam as condições de trabalho das mulheres solteiras e mães de família.

É evidente que as responsáveis pelas associações são muito sensíveis aos problemas sociais, particularmente visíveis nos meios populares parisienses. A imigração engendra uma desagregação, e da mesma forma uma dissolução dos laços sociais, e as résidentes sociales se preocupam em resolvê-los. Um trabalho como esse não se improvisa; ele é amplamente preparado nas escolas, onde um dos objetivos divulgados é combater o conjunto de grandes problemas sociais, a chamada questão social.

1914-1918: a guerra marca uma ruptura. Algumas mulheres morrem durante a guerra ao cuidar de doenças contagiosas e de epidemias, pagando assim um pesado tributo ao conflito. Uma parte dessa geração é fauchée. ${ }^{6}$ Durante a guerra, 71.192 francesas foram enfermeiras. Mais de 600 "morreram pela França", entre as quais 276 religiosas de todas as ordens; 2.500 foram "feridas"; 500 foram reformadas de guerra; 375 receberam a cruz da Legião de 
7 Cifras citadas por Juliette DELAGRANGE, 1938, p. 315.

${ }^{8}$ Movimento católico criado por Marc Sangnier, no final do século $\mathrm{XIX}$
Honra; 950, a Cruz da Guerra; 4.071, a medalha do reconhecimento francês; 4.615 , a medalha das epidemias; 313 , a medalha da ordem estrangeira por cuidados aos soldados das forças aliadas. ${ }^{7}$ Suas qualidades profissionais e seu sacrifício são reconhecidos e admirados durante anos, a tal ponto que, após a guerra, o exemplo da silloniste ${ }^{8}$ Geneviève Hennet de Goutel, morta de tifo na România em 1917, permanece como símbolo para a profissão.

Depois de 1918 a situação financeira das associações é catastrófica. A guerra arruinou os filantropos generosos e as necessidades de cuidados em serviço social são maiores que nunca. É aí que a filantropia norteamericana intervém de forma decisiva.

Bem antes da Primeira Guerra Mundial, norteamericanas morando na França se deslocam para visitarem as realizações da médica Anna Hamilton em Bordeaux e fazem um longo relato muito difundido nos Estados Unidos, na imprensa profissional médico-social. No momento do congresso de enfermeiras, em 1907, essas estrangeiras visitam as associações parisienses, como a ADAM e a Maison-Ecole fundada por Léonie Chaptal no 14 arrondissement (distrito) de Paris.

Em 1914, um grande número de norte-americanos (homens e mulheres), tanto na França como nos Estados Unidos, buscam por todos os meios ajudar a França em guerra, que passa por grandes dificuldades médico-sociais. Sobretudo as mulheres norte-americanas se organizam para intervir tanto no front (Anne Morgan e a médica Esther Lovejoy) como em postos de retaguarda (com ambulâncias, coletas de fundos, distribuição de roupas, etc.).

Em 1917, quando os Estados Unidos entram em guerra, suas ações se intensificam. Elas entram em contato com instituições médico-sociais, como a MSP e a Résidence Sociale. Quotidianamente, colaboram com as francesas e demonstram mútua admiração. É então muito natural que as norte-americanas convençam as francesas a irem aos Estados Unidos para levantar fundos com objetivo de expandir suas associações, mas nem todas as francesas partem, sobretudo as mais ligadas aos meios católicos, Léonie Chaptal e as fundadoras da ENS. No entanto, MarieJeanne Bassot, recebida em triunfo nos Estados Unidos, em 1919, é homenageada em vários artigos na imprensa norteamericana, onde é definida como a "Jane Addams francesa". Quanto a Anna Hamilton, ela consegue mobilizar todas as enfermeiras norte-americanas a fim de financiarem um internato para sua associação em memória das enfermeiras norte-americanas mortas durante a Grande Guerra: o American Nurses Memorial. 
9 Evelyne DIEBOLT e Jean-Pierre LAURANT, 1990.
Após uma pesquisa in loco com o intuito de combater a tuberculose e proteger os soldados norte-americanos, a missão Rockefeller se instala na França. Essa missão entra em contato com personalidades parisienses, contando com a colaboração de dirigentes da Associação de Enfermeiras Visitadoras (AIV) e com Léonie Chaptal. A missão desenvolve um ambicioso plano de intervenção e recebe importante suporte financeiro (um crédito de 2,3 milhões de dólares), o que a torna muito eficaz nas medidas de prevenção, criação de dispensários, etc. Por sua posição de exceção, a missão sensibiliza as autoridades políticas francesas para a necessidade de lutar contra os flagelos sociais. Para isso é necessário que a França seja dotada de infra-estrutura tanto administrativa quanto sanitária.

A ajuda financeira norte-americana no setor médicosocial é fundamental. Isso é muito difícil de contabilizar, porém não se pode deixar de citar os esforços financeiros concedidos pela missão Rockefeller a Anne Morgan e às mulheres que a rodeiam. ${ }^{9}$

1920-1940: o período entre guerras consolida as posições das mulheres nas associações. Após a guerra algumas mulheres retomam suas atividades e passam também a dirigir novas associações. Citamos Marie-Thérèse Vieillot, formada pela escola prática de serviço social do pastor Doumergue - ela dirigiu o Service Social de l'Enfance en Danger Moral (Serviço Social da Infância em Perigo Moral) (SSEDM) -, Eva Durrleman e Thérèse Matter, diplomadas pela escola da MSP, que fundaram e dirigiram em Lille o hospitalescola Ambroise Paré. Em Soissons, a AHSA é dirigida durante três anos (1925-1928) por Marguerite Oelker, diplomada da ADAM, e de 1928 a 1945 por Elisabeth Rouffiac, diplomada da MSP. A sillonista Madeleine Hardouin dirigiu o serviço social da Caisse de Compensation (Caixa de Compensação) da região parisiense.

\section{Laboratórios sociais e lugares de formação profissional}

As pioneiras concebem suas associações como modelos, e segundo elas suas experiências estão destinadas a serem copiadas ou imitadas. Elas estão convencidas de trazerem a solução para o mau funcionamento da sociedade por elas constatado, e nesse sentido inscrevemse na corrente utópica do século XIX.

Conscientes do fato de que suas associações deveriam perdurar e que isso requeria tempo, e considerando que seus procedimentos deveriam necessariamente ter continuidade e que, se esse trabalho não fosse reproduzido em grande escala, suas associações 
não passariam de gotas d'água no oceano, as pioneiras tiveram a idéia de formar seguidoras. Sendo as fundadoras freqüentemente autodidatas, elas logo compreenderam que nada seria possível sem um pessoal qualificado, competente e bem remunerado. Aliás, como estavam sendo confrontadas com as realidades quotidianas da ação social, in loco e no contexto social de então, elas não tiveram dificuldades em conceber programas de estudos destinados à formação profissional. Assim, suas práticas profissionais, heterogêneas, contribuíram para definir as realidades, os limites, e a dar um sentido ao que chamamos hoje de trabalho social.

As fundadoras abrem, então, escolas (na realidade, novas associações) que garantirão a continuidade do trabalho. Às vezes as escolas surgem alguns meses após a fundação da associação, mas quase sempre anos depois.

\section{A expansão do ensino feminino}

O ensino tem um lugar capital na obra e nas ambições das associações. Ele possui duas finalidades: formar profissionais ao mesmo tempo com uma boa cultura geral e capacidade técnica, além de oferecer possibilidades de trabalho para o pessoal diplomado. As duas primeiras décadas do século XX são caracterizadas pela expansão do ensino feminino. ${ }^{10}$

Léonie Chaptal, em 1905, responsabiliza-se pela direção de uma escola de enfermeiras: a Maison-école, que no período entre guerras propicia a elaboração do que futuramente serão os diplomas de Estado para profissionais da área médico-social. A criação dos diplomas de Estado para enfermeiras de hospitais e enfermeirasvisitadoras ocorre respectivamente em 1922 e 1925.

Na MSP, Anna Hamilton ambiciona formar diretoras de hospitais, públicos, privados ou de instituições, capacitadas a aprimorar, organizar, dirigir e gerenciar seus estabelecimentos; lembremos que ela própria era doutora em medicina. Elas freqüentam aulas teóricas, ministradas por médicos, no ambiente privilegiado do hospital-escola. Do ponto de vista prático, passam por todos os serviços dentro da instituição e aprendem a ampliar suas ações para fora dos muros do hospital, assegurando assim um tipo de assistência social antes da hora, apesar de serem "gardesmalades visiteuses" (enfermeiras-visitadoras).

Elas devem estar prontas para defender e pôr em prática suas idéias e concepções do trabalho social em um mundo essencialmente masculino e pouco propício, salvo algumas exceções, a levá-las em consideração. A MSP é uma escola de ponta que se torna modelo de hospital- 
"Apolline de Gourlet, M. l'abbé Viollet, Marie Diemer e MarieJeanne Bassot colocam em funcionamento a Escole ProGallia, em 1919. Em 1925-1926, a escola funciona com a das surperintendentes. A Escola ProGallia fecha em 1929. No mesmo ano, para continuar a oferecer a formação de residentes, abre-se a Escola da Accão Social de Levallois-Perret. Essa escola, que ganha o estatuto da Lei de 1901 é uma filial da Residence Social (FAYET-SCRIBE, 1990, p. 183).

${ }^{12}$ DIEBOLT, 1991.

${ }^{13}$ Véronique LEROUX-HUGON, 1992. escola e, além disso, a exigência de salário era a chave para o reconhecimento do trabalho social.

As outras escolas são muito atuantes, cada uma em seu campo específico: a ADAM, Maison-École, o ENS, a Escola Prática de Serviço Social, a Escola de Superintendentes de Fábricas, a Escola Pró-Gália, que se torna em 1929 a Escola da Ação Social de Levallois-Perret, ${ }^{11}$ são todas singulares. Mas como "résidentes sociales" (hoje incorporadas às assistentes sociais) elas se apropriam do discurso de M. Henri Bazire, pronunciado em janeiro de 1903: "è necessário que a résidente saiba de tudo, esteja a par de tudo, possa ensinar como aleitar um bebê, ou como abrir um processo..."

\section{O reconhecimento do diploma}

No período 1900-1920 as escolas patrocinam os estudos e fornecem diplomas. De fato somente três escolas - a MSP, a ADAM e a Maison-école - o fazem antes de 1914. Existe, então, uma hierarquia no momento da contratação. Observamos, por exemplo, que as municipalidades da França inteira recrutam apenas alunas formadas no modelo da Dra. Anna Hamilton. ${ }^{12}$ Durante a guerra, os diplomas de escolas especializadas na área social são concedidos às mulheres cujas atividades estão restritas a funções precisas: as superintendentes de fábricas, as résidentes sociales e as enfermeiras visitadoras da tuberculose.

A definição das novas profissões não acontece sem discussão: o termo mesmo de enfermeira (infirmière) gera debate, pois nele há uma conotação pejorativa, que suscita em alguns a preferência pelos termos nurse, de origem inglesa, ou garde-malade (pessoa que protege e cuida do doente). Depois da guerra de 140 termo infirmière prevalece devido ao elevado número de enfermos e mutilados, bem como devido à pressão da Assistência Pública de Paris, que prefere um pessoal médico-social submisso às hierarquias, tanto administrativa quanto médica, e recruta pessoal de enfermagem em um meio visivelmente mais popular que aquele, por exemplo, formado pela escola de Anna Hamilton. ${ }^{13}$ Até 1920 podemos estimar que o número de alunas diplomadas pelas diferentes escolas não chegava a 500 .

A Cruz Vermelha atrai numerosas francesas de origem aristocrática ou da grande burguesia. Porém, diferentemente do modelo nightingaliano, a formação é menor e oferece mais um verniz de cultura higienista do que uma verdadeira formação qualificada.

Entre 1922 e 1925, os diplomas de Estado de enfermeira de hospital e de enfermeira visitadora não são 
${ }^{14}$ DIEBOLT, 2000a

\footnotetext{
${ }^{15} \mathrm{Em} \mathrm{1938,} \mathrm{as} \mathrm{profissionais} \mathrm{do}$ trabalho social se defrontam com uma formação de dois anos limitada e empobrecida devendo fazer um ano de ensino médico, $\circ$ que as liga obrigatoriamente a esse setor vínculo, aliás, que as fundadoras das escolas sócias sempre combateram.
}

obrigatórios para se ter o direito de exercer a profissão, sendo fornecidas numerosas equivalências em função dos anos de prática profissional. Em reação surgem associações profissionais como a UCSS (1923), que tem por objetivo a "recatolização" do setor médico-social, reintroduzindo a noção de caridade cristã. ${ }^{14}$ A Union des Auxiliaires Sociales (UAS) (União de Auxiliares Sociais), fundada por André Butillard, e a ANIDEF, fundada por Léonie Chaptal, têm objetivos concorrentes, propondo uma ação social neutra no plano religioso, mas, como já vimos, com uma visão mais ampla da promoção do indivíduo: enquanto algumas associações têm em mente uma simples prevenção sanitária e social, outras propõem um verdadeiro trabalho de educação popular. São as diferentes concepções da área médico-social que se confrontam.

Em 1932, a criação do diploma de assistente social cristaliza a diferença entre a UAS e a UCSS, no que diz respeito às relações entre o setor médico e o social. Em 1938 a reformulação geral dos diplomas separa, quase que definitivamente, as profissões em dois grupos: as enfermeiras de hospital e as externas (vistadoras, superintendentes, ou "residentes"). As profissões mais generalistas foram abandonadas em detrimento das outras mais especializadas.

As leis estão longe de satisfazer a todos. Somente a UCSS as aprova, pois suas concepções do trabalho social coincidem com as competências sancionadas pelos diplomas de Estado. As pioneiras e seus discípulos não tinham uma concepção tão compartimentada, tão enquadrada, tão sistemática da divisão do trabalho. Defendiam, em cada caso, relacionar o setor médico e o social; o trabalho médico era valorizado pelo trabalho social e assim reciprocamente. No decorrer do tempo, essa complementaridade desejada foi contestada. ${ }^{15}$

\section{Qual é a atitude dos poderes públicos?}

Desde a sua criação, as associações solicitaram recursos ao Estado. As associações pedem o reconhecimento como sendo de utilidade pública para poderem receber heranças e subvenções. Dois anos após a criação da ADAM, a sua presidente, Mme. AlphenSalvador, obtém uma audiência com o presidente da República para apresentar a associação e obter subvenções. Na realidade, as subvenções raramente chegam da União, mas das municipalidades, que acham vantajoso encorajar, em suas regiões, as ações de benfeitoria praticadas por essas associações. As dotações das municipalidades para as associações são freqüentes, 
${ }^{16}$ DIEBOLT, 1991.

porém representam uma pequena parcela do orçamento. De 1900 a 1939, elas tendem a diminuir, e as associações cobram por seus serviços. Somente depois de realizarem missões nacionais, como no caso da AIV, na luta contra a tuberculose em 1916, é que as associações passam a receber subvenções importantes do Estado.

As associações fornecem pessoal para as grandes batalhas travadas pela República, e as municipalidades decidem laicizar seus hospitais. Laicizar um serviço hospitalar, tomando o exemplo de Florence Nightingale, era substituir as religiosas, cheias de boa vontade, por um pessoal leigo, feminino e formado. Esse pessoal tem como obrigação dirigir o hospital, e os médicos se limitam a visitas aos doentes e a prescrever os medicamentos. Para ter colaboradoras formadas, as associações abrem escolas, ainda mais que as alunas durante o curso prestam serviço no hospital. O exemplo do prefeito de Bordeaux, Dr. Lande, que laicisa o hospital municipal de sua cidade, se propaga. Uma dezena de prefeitos de toda a França faz o mesmo, como por exemplo das cidades de Béziers, Reims, Lorient e Philippeville (Argélia), recrutando um pequeno grupo de enfermeiras (duas ou três), que são encarregadas de realizar o processo de laicização. ${ }^{16}$ Essas mulheres têm acesso, então, a cargos de responsabilidade que nunca ousariam pretender ter. Será necessário esperar a criação, pelo Estado, da École de la Santé Publique de Rennes (Escola de Saúde Pública de Rennes), nos anos 1970, para que postos análogos sejam ocupados por mulheres.

O Estado recruta pessoal formado por essas associações. A idéia de recrutamento pelas forças armadas britânicas de enfermeiras competentes e formadas remonta à guerra da Criméia e à ação liderada por Florence Nightingale, ação que terá como conseqüência a reformulação estrutural dos serviços de saúde do exército inglês. Esse exemplo não deixará as autoridades francesas indiferentes, mesmo porque a Dra. Anna Hamilton pressiona para que enfermeiras formadas sejam recrutadas pelo exército francês. Um concurso é organizado em 1908, sendo oito enfermeiras convocadas, algumas das quais antigas alunas da MSP.

As municipalidades recrutam também esse pessoal, e as enfermeiras formadas pela Dra. Anna Hamilton são capazes de intervir fora do sistema hospitalar. Por exemplo, elas são chamadas pelas escolas privadas de Bordeaux para organizar um serviço de controle da saúde das crianças. Às vezes, quando um caso se torna grave, fazem visitas domiciliares para julgarem, por elas mesmas, as medidas mais eficazes a serem tomadas a fim de solucionar a situação. Então, se necessário, entram em contato com 
outras associações bordelesas capazes de darem continuidade ao trabalho. A municipalidade de Bordeaux adota o mesmo modelo para suas escolas públicas. ${ }^{17}$

Em Paris a Associação de Enfermeiras Visitadoras organiza o mesmo tipo de serviço para algumas escolas municipais, sendo essas enfermeiras remuneradas pela prefeitura do distrito (arrondisseme).

\section{Suas relações com o melo políitico}

Algumas mulheres interessadas na ação social conhecem muito bem o meio político e pertencem a ele, como Apolline de Gourlet, Lucie Félix-Faure Goyau, filha do presidente da República, Simone Loucheur, , filha do deputado, depois ministro, Louis Loucheur ou Léonie Gillet, mulher de um grande empresário que teve um representante de sua família candidato a cargo público.

Os políticos parecem aceitar de bom grado postos honoríficos que suas mulheres thes propõem nas associações. Deputados e ministros como Paul Strauss, Léon Bourgeois ou Justin Godard apoiaram largamente as associações médico-sociais. Eles estão perfeitamente conscientes dos limites de suas intervenções, sabendo muito bem que o verdadeiro trabalho é feito sem eles. Não esqueçamos as maravilhosas declarações de Théodore Tissier, vice-presidente do Conselho de Estado, em 1934, diante da assembléia geral do SSEDM: "Eu sou um homem que fala diante de mulheres que agem".

Para as associações, os políticos são aqueles que podem ajudá-las a encontrar subvenções importantes, mas essa busca nem sempre é coroada de sucesso e as associações são condenadas a cobrar pelos serviços para poder sobreviver.

Para a primeira geração de pioneiras, as relações com os políticos são relativamente fáceis. É certo que eles as encorajam, estudam e se inspiram em suas idéias, mas, sendo demorada a elaboração de um texto legislativo, somente a longo prazo elas obtêm sucesso.

No período da guerra, os políticos, conscientes da utilidade das associações, dirigem-se a elas para delegar serviços de amplitude nacional, como por exemplo a luta contra a tuberculose pelo AIV.

\section{Suas relações com o pessoal patronal}

As diretoras das associações se relacionam com numerosos empresários ou com o patronato social. Elas os conhecem devido às relações familiares, ou graças à convergência de idéias quanto à ação social a ser realizada, e muito freqüentemente fazem contato com 
${ }^{18}$ Cecile DAUPHIN, 1992; e Erika FLAHAULT, 2001

${ }^{19}$ Marie-Victoire LOUIS, 1994 empresas vizinhas de suas associações. O mais corrente é que procurem os empresários para pedir-lhes ajuda financeira, porém em alguns casos os empresários, compreendendo o significado do trabalho por elas realizado, utilizam a competência das pioneiras em proveito de seus próprios operários. Os exemplos mais flagrantes são o de Léonie Chaptal, que organiza dispensários contra a tuberculose para os operários, e o da refinaria Sommier com o incentivo dos seus próprios proprietários.

O caso das superintendentes de fábricas (corpo profissional criado em 1917) é muito singular. Elas são formadas para trabalhar exclusivamente no meio industrial, são contratadas por homens e estão sob as ordens deles. No interior da fábrica elas são encarregadas, sobretudo das operárias, porém, aquelas que receberam a responsabilidade de organizar as obras sociais nas empresas também são encarregadas dos operários. A partir dos anos 1930, uma parte do recrutamento das superintendentes se faz entre as filhas de engenheiros de grandes empresas.

\section{A inserção social dessas profissionais}

Aquelas que querem ocupar postos de direção optam por renunciar ao casamento. ${ }^{18}$ Elas fornecem razões consistentes para explicar essa escolha. Não devem estar sob nenhuma tutela para exercer as responsabilidades de postos de direção que disputam, e estão conscientes da fragilidade da fronteira entre atividades produtivas e atividades reprodutivas. As mulheres que escolhem a trajetória de se fazerem reconhecer pela competência profissional próxima das atividades domésticas não podem assumir a função reprodutiva, devendo permanecer solteiras para levar a vida independente à qual aspiram. Eu chamo essa atitude de "aceitar um celibato teorizado".

Elas se proíbem de ter uma vida sexual, pelo menos heterossexual. Numa época em que a contracepção é pouco fiável, é impossível que elas tenham uma vida sexual que possa resultar em uma gravidez fora do casamento. Assim, elas se subtraem do conjunto de mulheres que podem ser cortejadas, "presas" possíveis para os colegas masculinos com quem convivem. As tradições bufonas e vulgares deixaram traços nas canções e nos muros dos hospitais que são recobertos de grafites quase sempre obscenos. ${ }^{19}$ A médica Madeleine Pelletier faz apologia à virgindade alegando que somente assim é possível se ter uma verdadeira independência. Essas mulheres desejavam ao mesmo tempo escapar da tutela masculina, serem suas iguais pelo saber e recusavam a se submeter à dominação sexual. 
Poucas deixaram testemunhos das injúrias de que foram vítimas. Estudante de medicina, Anna Hamilton conta que passou uma noite trancada, por seus colegas, em uma sala de dissecação, cara a cara com um cadáver. Todas as pressões eram justificáveis para fazê-la parar seus estudos.

Debochar da pretensa "virgindade" dessas mulheres, identificada aos votos de castidade pronunciados pelas religiosas, era uma maneira de estigmatizar a recusa. Designar esse trabalho sob o termo de "vocação" denota uma falta de conhecimento das suas aspirações e reivindicações. Remarquemos que esse termo, ainda hoje, comporta uma conotação pejorativa.

Das quatro amigas estudantes na MSP, Alice Bianquis, Madeleine Rives, Éva Durrleman e Thérèse Matter, que desejam fundar um hospital-escola, as duas primeiras decidem se casar. Somente Éva Durrleman e Thérèse Matter, que permaneceram solteiras, fundam o hospital-escola desejado.

Algumas testemunham o desespero diante da escolha do celibato que a ordem social lhes impôs. Após ter trabalhado na SSEDM, Élisabeth Huguenin, em 1939, volta à Suíça e abre um consultório como "conselheira feminina", faz conferências e escreve numerosos artigos. Ela ressalta as dificuldades em ter ao mesmo tempo uma vida familiar e trabalhar nas áreas educacional e social. Educadora de profissão, Élisabeth Huguenin constata que essa independência profissional leva freqüentemente à solidão do celibato. Ela tem dificuldade de se resignar à condição de mulher sem lar e publica suas reflexões em vários escritos, como Missão da mulher (1941), A mulher diante de seu destino (1942), A educação da mulher (1945), A mulher só e Mulheres do amanhã (1946).

\section{Reagrupamento associativo: interlocutores de poderes públicos}

Rapidamente as associações compreenderam, embora nem sempre colocassem em prática, que era importante conjugar esforços. A influência do catolicismo é muito tênue nos primeiros anos que se seguem à guerra, mas o pacto nacional que esta causou enfraqueceu o anticlericalismo na França. Em 1923, o pessoal das associações médico-sociais católicas reagrupam seus membros em uma entidade profissional médica, a União Católica de Serviço Social (UCSS). Essa organização reúne, sob a tutela de Marie d'Airoles, as diferentes categorias do que, na época, é chamado de serviços de saúde no sentido amplo e que designamos hoje de médico-social. Vemos então se multiplicarem grupos que se posicionam em duas 


\begin{abstract}
${ }^{20}$ O Secretariado Católico das Obras Privadas Sanitárias e Sociais é uma associação, segundo a Le de 1901, fundada em 1930, que tem por objetivos servir de ligação entre as obras e os católicos que dedicam seu tempo, esforço ou recursos à higiene e a saúde, e constituir um centro de estudo e documentação.
\end{abstract}

correntes católicas distintas e concorrentes: uma é mais favorável à ação médico-social e outra vai mais em direção do "social", ou seja, voltada mais ao que diz respeito à educação humana em todos os aspectos.

Esses reagrupamentos trarão para o cenário francês a criação do Secrétariat Catholique des CEuvres Privées Sanitaires et Sociales (Secretariado Católico das Obras Privadas Sanitárias e Sociais), ${ }^{20}$ que Marie d'Airoles vai encorajar, e dentro do mesmo espírito, na cena internacional, o Comité International d'Étude des Associations Catholiques d'Infirmières et Assistantes MédicoSociales (CICIAMS) (Comitê Internacional de Estudos das Associações Católicas de Enfermeiras e Assistentes MédicoSociais), criado em 1930. A UCSS vê se oporem a ela duas outras associações profissionais "neutras" fundadas também por católicos, a Union des Auxiliaires Sociales (UAS) (União de Auxiliares Sociais), de Aimée Novo e Andrée Butillard, e a Association Nationale des Infirmières Diplômées d'État (ANIDEF) (Associação Nacional de Enfermeiras Diplomadas de Estado), criada em 1925 por Léonie Chaptal, que defende o diploma de Estado que regulamenta a profissão, mas acredita que a enfermeira deve ser dedicada até a abnegação. O que está em jogo é o controle do setor médico na formação dos alunos: com efeito, a UAS e a ANIDEF estimam que as exigências para obtenção de diploma propostas pela UCSS privilegiam o ensino médico em detrimento do exclusivamente social.

Em outras palavras, os meios católicos fixaram como objetivo manter e reforçar a representação confessional no seio dos órgãos internacionais de serviço social, afirmando assim uma concepção confessional diante da corrente "neutra". O que também estava em jogo de forma velada era o controle do setor: o serviço social é um serviço público ou um lugar de caridade cristã universal?

\section{Um tímido engajamento do Estado}

Entre 1920 e 1939, o Estado torna-se mais intervencionista, mas não pretende substituir a iniciativa privada. Ele recusa, por exemplo, continuar a obra do SSEDM, porém se encarrega de numerosos doentes e mutilados da Grande Guerra e se responsabiliza pelos problemas da tuberculose e da infância. No entanto, a partir de 1930, a crise econômica o obriga a estar mais presente. Assim, a lei sobre os seguros sociais permite um reembolso parcial dos tratamentos de saúde, o que melhora de modo decisivo a saúde pública e enche os cofres das associações prestadoras de serviços, como a ADAM, a MSP ou a Residência Social de Levallois-Perret. 
${ }^{21}$ No evento Journées Sociales, organizado pela UCSS entre 19 e 21 de fevereiro de 1928, uma comunicação sobre o trabalho social nos Estados Unidos revelou - método do case work. A conferencista doutora Henry o definiu da seguinte forma: "Uma única assistente social em cada família será responsável pela reorganização social total, como a enfermeira-visitadora polivalente é responsável de toda a higiene familiar. [...] Esse método científico do trabalho caritativo que busca ser pessoa e profundo é chamado método do case work" (Bulletin de l'UCSS n. 3, mai-juin 1928, p. 114). MarieThérèse Vieillot vai utilizar esse método, que aprendeu nos Estados Unidos, no SSEDM.

22 De 1940 a 1945, o número de associações se torna tão importante que elas não podem mais resolver qualquer que seja o problema, individualmente. Elas são obrigadas a se agrupar criando federações, institucionalizando-se. É sob essa ótica que a UNIOPSS é criada em 1947.
Da mesma maneira, em 1932, finalmente é votado um projeto que vinha se arrastando por mais de dez anos: a lei instituindo auxílio-família, pago pelas empresas.

Nos anos 30 os seguros sociais trouxeram uma renovação financeira às associações que patrocinaram alguns serviços. Mas a situação é difícil.

Temos confirmação disso quando, em 1938, Mme. Olga Spitzer, do SSEDM, propõe ao Ministério da Justiça a retomada do serviço social que ela criou e manteve até aquele momento. Da parte do Ministério há uma tentativa de recusa ao pedido, porém ela obtém uma importante subvenção, mas bem menor do que a que necessita para continuar o trabalho.

De 1920 e 1940, a maioria das profissionais obtém seus registros pelos anos de experiência e não por educação formal: vemos então uma democratização do setor médico-social, tanto no recrutamento do pessoal como no aumento dos serviços e auxílios, o que leva a certa indefinição na filosofia da profissão. Essa indefinição favorece a proposta ideológica da UCSS, que defende a concepção de serviço social baseada nos valores vocação, benevolência e dedicação, que já prevalecia desde o final do século XIX. Os dirigentes da UCSS e da hierarquia católica não querem ter qualquer questionamento, por menor que seja, da definição da profissão e bloqueiam atitudes independentes, melhores salários e inovações, como por exemplo a técnica americana do case work. ${ }^{21}$

Após as leis de 1938 que separam claramente os diplomas de enfermeira e de assistente social, as "anônimas" da terceira geração são as alunas das numerosas escolas criadas nesse setor.

\section{A vitória do Welfare State?}

O decreto de 4 outubro de 1945 instituindo a Sécurité Sociale (Previdência Social) foi considerado pelas diversas associações como uma ameaça. De fato, Pierre Laroque e seus colaboradores pretendiam não utilizar os serviços do corpo associativo. Porém, seria necessário muito dinheiro para reconstruir o corpo sanitário e social organizado pelas associações.

O Estado, então, se vê obrigado a recorrer às associações e as convocam para que assumam algumas atividades no setor público. Com o pedido sem recusa, as associações, temerosas, se organizam em uma federação liderada pela UNIOPSS. ${ }^{22}$ A liderança da UNIOPSS pode ser explicada pelo fato de ter se tornado, desde sua criação, parceira da Union Nationale des Caisses d'Allocations Familiales (UNCAF) (União Nacional das Caixas de Auxílio 
${ }^{23}$ Desde 1921, o sistema de auxílio-família - no início um simples órgão contábil considera indispensável criar um serviço social. Madeleine Hardouin, sillonniste, formada pela Escola de Superintendentes de Fábricas, fica na chefia desse orgão até 1948 , fazendo dele um verdadeiro serviço piloto e o desenvolvendo de modo considerável (Ysabelle de HURTADO, 1966).
${ }^{24}$ Inspetora geral do Serviço Social das Forças Armadas (Jean de VERBIZIER, 1995).

${ }^{25}$ DIEBOLT, 1982.
Familiar). ${ }^{23}$ A penetração de sindicatos politizados como a CGT no seio dos organismos oficiais de Previdência Social é denunciada. Eles ficam na defensiva, afirmando que é necessária a criação de um espaço de negociação para que a colaboração com os poderes públicos se torne efetiva. A normalização da relação poder públicoassociações acontece em 1965, e pouco a pouco os poderes públicos repassam para as associações mais e mais tarefas - a acolhida de franceses repatriados da guerra da Argélia é um exemplo.

Se nos primeiros meses de existência a federação deve negociar com o Estado para defender as associações privadas, pelo menos ela encontrou interlocutores prontos a aceitar compromissos. Hoje o papel decisivo da ajuda financeira concedida pelo Estado tem permitido o desenvolvimento do meio associativo nessa área.

A partir de 1945, os empregos femininos oferecidos são numerosos e variados, como o de tutora profissional nas allocations familiales (auxílios-família), o de conselheira em economia familiar e social, puericultora, jardinière d'enfants (atualmente chamadas de educadoras infantis) e o de conselheira para o trabalho, e as possibilidades de trabalho se ampliaram das áreas da cultura e médica para as da justiça e da educação. O celibato não é mais uma regra. $A$ segunda reconstrução da França exige muitos braços. Novas chances são oferecidas para mulheres que trabalham no setor médico-social, e numerosas são aquelas que querem mostrar um espírito de iniciativa, por exemplo organizando um serviço, redigindo monografias tendo como tema o meio profissional no qual elas trabalham.

Porém, nesse meio não há mais espaço para grandes personalidades, idéias e ambições, sendo agora necessárias trabalhadoras assalariadas regulares e anônimas. Dentre as mulheres assalariadas, as que se casam e têm filhos são cada vez mais numerosas.

Apesar de serem encontradas algumas figuras de destaque, como Jane Sivadon, ${ }^{24}$ não há mais personalidades fortes. A base do recrutamento se alargou. Nos anos 1950, por exemplo, as filhas de agricultores recebiam bolsas da Mutualité Sociale Agricole (Associação Social Agrícola) para desenvolverem estudos de assistente social. Em seguida elas são contratadas por esse organismo, que busca ampliar seu serviço social. ${ }^{25}$ Nas associações caritativas médico-sociais, o poder é imperceptivelmente transferido para as mãos dos homens. Será o preço a ser pago para que se instaure um trabalho assalariado regular e anônimo nesse setor?

O período pós-Segunda Guerra Mundial é de expansão e de consolidação, graças aos novos modelos 
${ }^{26}$ Gisela BOCK, 1992, p. 403.

${ }^{27}$ Marie-Noel VALLS-LACROIX 1989. de financiamento do setor social. Em 1945, a criação da Sécurité Sociale tem por objetivo redistribuir os ganhos no país, sendo esse setor tomado em massa pelas mulheres, como campo de estudo e trabalho. Elas são as principais beneficiárias dos novos tipos de auxílio. "Em 1946, a Quarta República aumenta o montante dos auxílios para a infância (chamadas de prestations familiales, auxílios-familia) e restabelece o depósito direto dos auxílios-maternidade financiados pelo Estado. Nos anos 1950 o auxíliomaternidade foi estendido, particularmente para a zona agrícola, às esposas de trabalhadores independentes, que até então não tinham direitos."26

Vê-se então, após a Segunda Guerra Mundial, um fenômeno idêntico àquele dos anos 1920: a explosão do número de pessoal, de novas associações, de escolas e de serviços sociais. Progressivamente o diploma de Estado torna-se obrigatório. Essa guerra, como a anterior, vitaliza o setor social. Alguns serviços são novamente centralizados e operam em escala nacional, mesmo se tenham ramificações departamentais ou locais. Um dos exemplos mais significativos é o da Associação Social Agrícola, presente em todos os departamentos. Na prática, as ações de prevenção são direcionadas essencialmente às mulheres, pois são sobretudo elas que garantem a organização da vida quotidiana e a manutenção dos laços e da ordem social.

Nos anos 1950, os serviços sociais, ainda privados, dependem das subvenções dadas pelos organismos parapublics. Eles recebem regularmente dinheiro graças à criação da Previdência Social e se tornam prestadores de serviços. Nesse novo tipo de relação, as obrigações das associações são codificadas e regularizadas. É a UNIOPSS que mostra às associações seus direitos e suas obrigações (1960). Da mesma maneira, as profissões, cujo reconhecimento vinha se arrastando há 20 anos (de 1945 a 1970), sobretudo no setor privado, são agora institucionalizadas.

A ruptura entre o setor médico e o setor social está definitivamente consumada, mesmo com algumas assistentes sociais colaborando, num mesmo serviço, com as enfermeiras. Estas últimas recuperam os serviços da saúde escolar, porém sob a autoridade cerrada dos médicos escolares. Quanto às assistentes sociais, elas conseguem preservar uma relativa independência: seus superiores hierárquicos são outras assistentes sociais ou administradores de instituições públicas ou parapublics. A partir de 1950 os empregos se estabilizam, e o valor dos salários pagos situase entre $\mathrm{o}$ dos altos funcionários e $\mathrm{O}$ das operárias. ${ }^{27}$ As profissões médico-sociais conseguiram uma penetração 
28 "Na França do pós-guerra, mais do que em outro país europeu, uma parte substancial da verba nacional foi distribuída para as mulheres por meio de auxílios para as mães" (BOCK, 1992, p. 406).

${ }^{29}$ Nadine LEFAUCHEUR, 1992, p. 424. expressiva, tanto pelo viés do ensino, quanto por sua utilização, contribuindo para a socialização do trabalho assalariado da mulher, solteira ou casada.

As mulheres pioneiras estão na origem da noção do serviço social. Elas colaboraram para a criação das profissões médico-sociais, que contribuíram para o desenvolvimento nesse setor de um mercado de trabalho exclusivamente feminino. Os serviços sociais destinam-se, sobretudo, às mães e às crianças, assim como às famílias. ${ }^{28}$ No que se refere ao emprego, serviços ou auxílios sociais, pode-se afirmar que as mulheres foram as grandes beneficiárias do Welfare State à francesa. Algumas empregaram em relação a elas mesmas a metáfora ambígua de um "casamento com o Welfare State"... Essa talvez seja uma maneira de constatar que a submissão das mulheres a seus maridos foi substituída pela submissão ao Estado. ${ }^{29}$

Nos anos 1970, o setor sanitário e social ganha uma expansão que não tinha conhecido até então, guardando ele a estrutura associativa. Nas associações as mulheres ocupam a maioria dos empregos, e o emprego feminino, nesse setor, corresponde às características de emprego para mulheres pouco qualificadas. O emprego é precário, e as mulheres geralmente não trabalham em tempo integral. Elas quase não têm possibilidades para se qualificar e por isso têm pouca oportunidade de promoção, sendo suas remunerações próximas do SMIC (salário mínimo).

Com o passar do tempo as relações se ampliam. As associações acabam por passar, via UNIOPSS, quase inteiramente para as mãos dos homens. Entre os 10-20 membros fundadores que dirigem a UNIOPSS, nós encontramos somente duas mulheres: Mme. Edmond Viollet, que dirige a Association d'Aide aux Mères (ADM) (Associação de Ajuda às Mães), e Mme. de Paillerets, que representa a Cruz Vermelha francesa. No momento em que se organiza a Previdência Social (orgão ligado ao Estado), a UNIOPSS vai defender as posições ideológicas do setor privado em relação ao poder do setor público. Mesmo sendo criada no rastro do MRP, que não exclui as mulheres da vida política, essa nova União escapa total e definitivamente às mulheres. O valor do salário de alguns membros dirigentes da UNIOPSS está no patamar dos altos funcionários do Estado, como Charles Blondel, conselheiro de Estado, ou Jacques Guérin de Vaux, inspetor de finanças. Isso leva a uma relação com - Estado totalmente diferente daquela do período precedente: trata-se agora de uma parceria.

No caso do setor médico social, um outro fenômeno intervém. Graças à abertura das profissões, as populações femininas visadas pela ação das associações encontram 
30 Dados obtidos no Institut National de la Statistique et des Etudes Economiques (INSEE).
${ }^{31}$ ARCHAMBAULT, 1999, p. 18 SIRENE é abreviatura da instituição que registra as associações na França. inserção no mundo do trabalho médico-social, o que foi um ganho bem mais considerável que receber auxílios, benefícios, aliás, que não eram excludentes.

O setor associativo hoje é largamente utilizado pelos poderes públicos. As possibilidades de renovação, de criação, de inventividade são relativamente limitadas, o que não impede os indivíduos de se lançarem nas aventuras associativas com satisfação. Citemos por exemplo os Restos du Cœur (Restaurantes do Coração), onde 40.000 voluntários distribuem 58 milhões de refeições por ano, para 540.000 beneficiários, dos quais 24.000 são bebês de menos de 18 meses, mas se trata, sempre, de casos de representação da gestão pragmática da pobreza e da miséria.

Em 2001, o setor médico-social conhece uma nítida expansão no número de associações e em número de empregos. Em 1989, contam-se 90.000 associações no setor sanitário e social. "Temos que observar que o emprego aumentou mais do que o dobro no setor social entre 1980 e 1990, e depois continua a progredir no mesmo ritmo. Em 1989, o setor sanitário conta com 80.000 assalariados; o setor social, 200.000. Em 1995, as associações de serviços sociais empregam 380.000 pessoas em tempo integral, ou seja, tanto quanto em postos de telecomunicações." ${ }^{30}$

O setor social foi construído pelas pioneiras utilizando a forma associativa, e hoje observamos que o seu modo de funcionamento continua o mesmo. Ele cresceu segundo as mesmas formas e as orientações dos seus primórdios, como coloca em evidência Edith Archambault: "O setor de serviço social é o único domínio da atividade onde o emprego é majoritariamente associativo: as associações empregam, com efeito, $58 \%$ dos trabalhadores sociais. Os serviços sociais têm um peso econômico muito importante no setor associativo. Representa $21 \%$ das associações inscritas no SIRENE, $33 \%$ das despesas correntes e sobretudo $40 \%$ do emprego total do terceiro setor". ${ }^{31}$

\section{Um desmoronamento dos empregos femininos}

As profissões sanitárias e sociais são ainda hoje muito feminizadas. Tomemos o exemplo das enfermeiras: em 2001, dos 300.000 enfermeiros/as diplomados/as, $84 \%$ são mulheres (números do Ministério da Saúde). Nas profissões de ajuda em domicílio, a proporção de trabalhadores do sexo feminino é de $99 \%$.

As mulheres que trabalham nesse setor vêem suas remunerações estagnarem, suas condições de trabalho se degradarem, e as grandes greves não conseguiram obter 
${ }^{32}$ Danièle KERGOAT, 1992. 33 Jacqueline HEINEN e Josette TRAT, 1997. a valorização desejada pela categoria. As greves de enfermeiras de 1988-198932 e a de assistentes sociais, em 1991-1993,33 são os sinais mais recentes desse problema, deixando um grande sentimento de incompreensão e amargura. Foram criados numerosos empregos precários, e os postos ocupados pelo pessoal qualificado foram preenchidos por mulheres menos qualificadas. Para aquelas e aqueles que são qualificados, as condições de trabalho se tornaram mais difíceis. A carga de trabalho continuou a mesma, mas o pessoal foi reduzido e certas obrigações tiveram que ser delegadas ao pessoal formado de forma precária.

\section{A masculinização dos cargos de direção}

Quem está na direção desse setor? De 1947 a 2001 , a UNIOPSS agrupa quase todas as associações do setor sanitário e social. A análise do quadro dirigente da UNIOPSS de 1948 aos nossos dias mostra que não houve nenhuma mulher na direção da federação.

O que aconteceu em escala local? Desde a fundação da UNIOPSS foram abertos, em várias regiões da França, escritórios regionais congregando obras e organismos sanitários/sociais privados (URIOPSS).

Qual é o lugar que ocuparam ou ocupam as mulheres hoje dentro das URIOPSSs. Qual evolução vemos se esboçar?

De 1947 a 2001 pode se verificar que as presidentes não chegam a $5 \%$ ou $6 \%$ do conjunto do pessoal dirigente das URIOPSS. Uma presidente é uma voluntária designada pelas outras presidentes das associações que aderem à URIOPSS. Isso requer então uma grande disponibilidade: é necessário continuar a ser presidente da associação que representa, para ainda assumir a presidência da URIOPSS.

Entre 1947 e 2001 , no que se refere ao número de mulheres em cargos de diretoria e pessoal assalariado, a maior cifra (40\%) é atingida no momento da criação da federação, em 1949. Depois disso, a maior cifra do decênio foi de $30 \%$ em 1998.

A proporção de mulheres diminui, até atingir um mínimo, em 1979, de 2,2\%. Como explicar essa queda? Percebemos que em 1979 as primeiras mulheres recrutadas não estão mais na direção das URIOPSS: elas se aposentaram. Quando foram substituídas, o foram por homens, mas pouco a pouco as mulheres são recrutadas novamente.

Eu pude perceber que de 1947 a 2001 as mulheres foram devagar e imperceptivelmente eliminadas dos postos de direção do setor sanitário e social que elas haviam 
${ }^{34}$ DIEBOLT, 1999.

${ }^{35}$ BARD, 2001, p. 82.

${ }^{36}$ LEROUX HUGON, 1992.

${ }^{37}$ BARD, 2001 , p. 80 criado. ${ }^{34} \mathrm{~A}$ observação de Christine Bard sobre o setor associativo sanitário e social é bastante pertinente: "É o emprego das mulheres que protege os homens da desqualificação nas fábricas e nos escritórios" 35 em lhes reservando os postos mais qualificados e vantajosos. Ao fundar o setor associativo sanitário e social, essas mulheres abriram então um campo de exercício profissional valorizado para os homens. Em uma avaliação da complexidade das situações que resultaram na eliminação das mulheres da elaboração e da aplicação de políticas sanitárias e sociais, não se poderia afirmar que foram as próprias mulheres que se colocaram nessa posição de "telhado de vidro"?

Essas mulheres não deixaram cartas, escritos? O que houve com seus arquivos? Eu detectei uma forte preocupação para que não escutemos suas vozes. Por seus esforços em se fazerem reconhecer como mulheres qualificadas no trabalho do bem-estar social, elas exprimem de um jeito não espetacular uma forma de feminismo que passou despercebido. As mulheres organizam as hierarquias profissionais no hospital por sua concepção de hospitaisescolas e nos serviços sociais. Para elas, o desaparecimento da dominação dos homens sobre as mulheres deve ceder lugar a um mundo comum composto, heterogêneo, enriquecido pela contribuição dos dois sexos. As relações entre os sexos não são mais hierarquizadas, mas iguais e paralelas no seio de um mesmo mundo.

O silêncio que ainda hoje reina em torno das realizações dessas mulheres é revelador do aspecto profundamente subversivo de suas concepções. As novas relações sociais entre os sexos que elas tentaram instaurar não foram compreendidas nem por seus contemporâneos, nem pelos pesquisadores de hoje. Véronique Leroux-Hugon ${ }^{36}$ qualifica Anna Hamilton de "burguesa" que se oporia à ascensão social de jovens provincianas que queriam se tornar enfermeiras. A "enfermeira proletária" não teria nada das reivindicações do CNFDH. Para Christine Bard, "a laicização dos profissionais de saúde se faz sem grande ruptura com o espírito anterior, que valorizava o sacrifício, a abnegação e dedicação. Por seus trajes, as enfermeiras pareciam, aliás, com as religiosas". ${ }^{37}$ Ao contrário, elas recusam a idéia do sacrifício e da abnegação e recusam a identificação com as religiosas.

Há um século, o estatuto profissional que as agrega nunca realmente as reconheceu. Esse mal-estar se exprime de modo recorrente por manifestações e greves. As greves 
${ }^{38}$ KERGOAT, 1992.

${ }^{39}$ HEINEN E TRAT, 1997. que sacudiram o setor de enfermeiros, em 1988-1989,,$^{38} \mathrm{e}$ a greve das assistentes sociais, em 1991-1993,39 são sinais mais recentes disso.

Tradução de Fátima Sebastiana Gomes Lisboa Revisão da tradução: Maria Lucia de Barros Mott

\section{Siglas mencionadas no texto}

ADAM: Association pour le Développement de l'Assistance aux Malades - Associação para o Desenvolvimento da Assistência aos Doentes em Paris

AHSA: Association d'Hygiène Sociale de l'Aisne - Associação de Higiene Social de Aisne

AIV: Association des Infirmières Visiteuses de France - Associação de Enfermeiras Visitadoras da França

ANIDEF: Association Nationale des Infirmières Diplômées d'État - Associação Nacional de Enfermeiras Diplomadas de Estado

ASUSS: Association des Surintendantes d'Usine et des Services Sociaux - Associação de Superintendentes de Fábricas e Serviços Sociais

CICIAMS: Comité International d'Étude des Associations Catholiques d'Infirmières et Assistantes Médico-Sociales - Comitê Internacional de Estudos das Associações Católicas de Enfermeiras e Assistentes Médico-Sociais

EPSS: École Pratique de Service Social - Escola Prática de Serviço Social

ENS: Ecole Nationale Supérieure - Escola Nacional Superior

HAPL: Hôpital-École Ambroise-Paré de Lille - Hospital-Escola Ambroise-Paré de Lille

MEIP: Maison-École d'Infirmières Privées - Casa-Escola de Enfermeiras Privadas

MS: Maisons Sociales - Lares Sociais

MSP: Maison de Santé Protestante - Casa de Saúde Protestante

RSLP: Résidence Sociale de Levallois-Perret - Lar Social Levallois-Perret

SMIC: Salaire Minimum Interprofessionnel de Croissance - Salário Mínimo Profissional de Crescimento

SSEDM: Service Social de l'Enfance en Danger Moral - Serviço Social da Infância em Perigo Moral

UAS: Union des Auxiliaires Sociales - União de Auxiliares Sociais

UFC: Union Familiale de Charonne - União Familiar da Charonne

UCSS: Union Catholique de Service Social - União Católica de Serviço Social

UNCAF: Union Nationale des Caisses d'Allocations Familiales - União Nacional das Caixas de Auxílio Familiar

326 Estudos Feministas, Florianópolis, 13(2): 305-329, maio-agosto/2005 


\section{Referências bibliográficas}

ARCHAMBAULT, Edith. "Le secteur associatif en France et dans le monde". In: BLOCH-LAîNÉ, François (dir.). Faire société. Les associations au cœur du social. Paris: Syros, 1999.

BARD, Christine. Les femmes dans la société française, XXe siècle. Paris: Armand Colin, 2001. BOCK, isela. "Pauvreté féminine, droits des mères et États providence". In : DUBY Georges; PERROT Michelle. Histoire des femmes. Paris: Plon, 1992. Tome V. p. 381-409.

DAUPHIN, Cécile. "Femme seule". In: FRAISSE Geneviève; PERROT Michelle. Histoire des femmes. Paris: Plon, 1992. Tome IV.

DELAGRANGE, Juliette. "Le point sur la situation des infirmières en France". L'Infirmière Française, n. 179, 1938.

DIEBOLT, Evelyne. Le Service social de la Mutualité agricole. A.T.P.-C.N.R.S. d'histoire du service social dirigée par Yvonne Knibiehler, 1982.

La Maison de Santé protestante de Bordeaux 1863-1934, vers une conception novatrice des soins et de l'hôpital. Toulouse: Erès, 1989.

"Les Laïcisations hospitalières d'inspiration protestante". In: POIRIER, Jacques; SIGNORET, Jean-Louis (dir.). De Bourneville à la sclérose tubéreuse. Paris: Flammarion, 1991. p. 83-89.

. Les associations face aux Institutions: les femmes dans l'action sanitaire, sociale et culturelle 1900-1965. Thèse d'Etat es Lettre et Sciences humaines, Université Paris VII, juin. 1993.

De la quarantaine au quaranténaire: histoire du foyer de postcure psychiatrique de l'Elan. Paris: CAT de l'Elan, 1997.

. Les femmes et les associations: la prise de décision. Paris: Rapport Service des Droits des Femmes, 1999.

"Les femmes catholiques: entre église et société". In: CHADWICH, Kay (ed.). Catholicism, Politics and Society in Twentieth-Century France. Liverpool University Press, 2000a. p. 219-243.

"Femmes protestantes faces aux politiques de santé publique 1900-1939". Bulletin de la Société de l'Histoire du Protestantisme Français (BHSP), tome 146, Femmes protestantes au XIXe et au XXe siècles, janvier, février, mars 2000b.

"Women and Philanthropy in France: from the Sixteenth to the Twentieth Centuries".

In: MCCARTHY, Kathleen D. (ed.). Women, Religion and Civil Society. Indiana University Press, 2001a. p. 29-63.

"1901-2001, femmes et hommes dans la naissance et l'expansion du secteur sanitaire et social. De la coopération à la compétition?". In: DIEBOLT, Évelyne; DOUYEREDEMULANAERE, Christiane (dir.). Un siècle de vie associative: quelles opportunités pour les femmes? Colloque International Tenu à l'Assemblée Nationale et au CHAN, 14-15-16 mai 2001, pour la commémoration du centenaire de la Loi 1901. Paris: éd. Femmes et Associations, $2001 \mathrm{~b}$.

. Les femmes dans l'action sanitaire, sociale et culturelle, 1901-2001. Les associations face aux institutions. Paris: éd. Femmes et Associations, 2001c. Préfaces de Michelle Perrot et d'Emile Poulat.

"Les Américains en Picardie". La Lettre de l'Historial, Dossier, éd. Conseil Général de la Somme, n. 16, p. 4-5, avril 2002a. 
“Archives d'associations: une mémoire 'émiettée' une mémoire 'étouffée'. État des lieux". In: DIEBOLT, Évelyne; DOUYERE-DEMULANAERE, Christiane (dir.). Un siècle de vie associative: quelles opportunités pour les femmes ? Colloque International Tenu à l'Assemblée Nationale et au CHAN, 14-15-16 mai 2001, pour la commémoration du centenaire de la Loi 1901. Paris: éd. Femmes et Associations, 2002b.

. "Militantisme dans les associations sanitaires et sociales". Chronique Féministe. Toutes Engagées ?, Bruxelles, Université des femmes, n. 77/79, janv./avril, p. 33-39, 2002c.

DIEBOLT, Evelyne (dir.). "La femme soignante". Pénélope, pour l'Histoire des Femmes, n. 5 , p. 3-5, 1981.

DIEBOLT, Evelyne; COLLIERE, Marie-Françoise (dir.). "Pour une Histoire des soins et des pratiques soignantes", Cahier de l'AMIEC, n. 10, mai. 1988.

DIEBOLT, Evelyne; COQUEREL-JEANNEAU, Valérie; WEINBERGER, Monique. Les Lucines des Lilas et le baby blues. Paris: Hachette, 1980. coll. L'Echappée Belle.

DIEBOLT, Evelyne; DOUYERE-DEMULANAERE, Chistiane (dir.). Un siècle de vie associative : quelles opportunités pour les femmes? Colloque International Tenu à l'Assemblée Nationale et au CHAN, 14-15-16 mai 2001, pour la commémoration du centenaire de la Loi 1901. Paris: éd. Femmes et Associations, 2002.

DIEBOLT, Evelyne; LAURANT, Jean-Pierre. Anne Morgan, une américaine en Sissonnais (19171952). Soissons: AMSAM, 1990.

DIEBOLT, Evelyne; PEROT, Michelle. "Sortir". In: FRAISSE, Geneviève; PERROT, Michelle (dir.). Histoire des femmes, le XIXe siècle. Paris: Plon, 1992. Tome IV. p. 467-494.

DIEBOLT, Evelyne; ZYLBEBERG-HOCQUARD, Marie-Helene. Marcelle Capy-Aline Valette. Femmes et travail au dix-neuvième siècle. Paris: Syros, 1984. Coll. Mémoire des Femmes.

FAYET-SCRIBE, Sylvie. Associations féminines et catholicisme, de la charité à l'action sociale $X I X^{e}-X X^{e}$ siècles. Paris: Les Editions Ouvrières, 1990.

FLAHAULT Erika. "Le Célibat come élément d'intégration des femmes dans le salariat au 19 ème siècle". Cahiers des Annales de Démographie Historique, Paris, n. 125, p. 86-109, 2001.

GARRIGOU-LAGRANGE, Jean-Marie. Recherches sur les rapports des associations avec les Pouvoirs publics. Paris: Librairie Générale de Droit et de Jurisprudence, 1970. . Les Associations. Paris: P.U.F., 1975.

HEINEN, Jacqueline; TRAT, Josette. Hommes et femmes dans le mouvement social. Paris: L'Harmattan, 1997. Cahier du GEDISST.

HURTADO Ysabelle de. "Le service social tel que je l'ai vécu". Informations Sociales, n. 36, p. 9-23, avril-mai 1966.

KERGOAT, Danièle (dir.). Les infirmières et leur coordination. Paris: Éd. Lamarre, 1992.

LEFAUCHEUR, Nadine. "Maternité, famille, État". In: DUBY, Georges; PERROT, Michelle. Histoire des femmes. Paris: Plon, 1992. Tome V. p. 414-430.

LEROUX-HUGON, Véronique. Des Saintes laïques. Les infirmières à l'aube de la llle République. Paris: Science en Situation, 1992.

LOUIS Marie-Victoire. Le Droit de cuissage en France 1860-1930. Paris: L'Atelier, 1994.

PERETZ, Henri. "La Création de l'enseignement secondaire libre de jeunes filles à Paris (19051920)". Revue d'Histoire Moderne et Contemporaine, n. 32, p. 237-275, 1985.

POUJOL, Genevève. La Dynamique des associations, 1844-1905. Paris: Société des Amis du Centre d'Études Sociologiques, 1978.

"Genèse des associations". Questions de Cultures au Québec, n. 8, p. 8-25, 1989.

VALLS-LACROIX, Marie-Noel. Praticiens du secteur sanitaire et social, qui êtes-vous? Paris: Les Éditions Ouvrières, 1989.

VERBIZIER Jean de. Hommage à Jane Sivadon, discours prononcé à l'ET SUP. Paris, 7 nov. 1995. 
[Recebido em janeiro de 2005 e aceito para publicação em fevereiro de 2005]

\begin{abstract}
A History of Social Work: The Birth and Growth of the Sanitary and Social Associative Sector in France (1901-2001)

Abstract: Without civil rights, unable to vote, prevented from joining a labor union and hardly having a voice in political parties, women found in the July $1^{\text {st }}, 1901$ Law of Freedom of Association a space through which they could obtain citizenship at once. Since the law was promulgated in 1901, they have created innumerous social and sanitary associations, and pioneered the building of a concept of social work. They did all they could to create new jobs, which contributed to the exclusively feminine participation in the sector. Thanks to the progressive opening up of the professions, the feminine population, target of the activities of such associations, managed to enter the field of health and social work. In the 1970's, the sanitary and social sector experienced an unprecedented expansion, maintaining its associative structure. In these associations, women occupy the majority of positions, but they are low-qualified jobs. As the sector becomes increasingly institutionalized, women see their jobs being gradually taken over by men. This associative sector, nowadays, is widely employed by governments to implement social policies and to fight all forms of poverty and emergency situations.

Key Words: feminine associations, citizenship, social work.
\end{abstract}

